\title{
Associations between diet and mental health using the 12-item General Health Questionnaire: cross-sectional and prospective analyses from the Japan Multi- Institutional Collaborative Cohort Study
}

Naoki Choda ${ }^{1 *} \mathbb{D}$, Kenji Wakai ${ }^{1}$, Mariko Naito ${ }^{1,2}$, Nahomi Imaeda $^{3}$, Chiho Goto $^{4}$, Kenta Maruyama ${ }^{1}$, Yuka Kadomatsu', Mineko Tsukamoto', Tae Sasakabe ${ }^{1,5}$, Yoko Kubo ${ }^{1}$, Rieko Okada', Sayo Kawai ${ }^{1,5}$, Takashi Tamura', Asahi Hishida', Kenji Takeuchi ${ }^{1}$, Atsuyoshi Mori ${ }^{6}$ and Nobuyuki Hamajima ${ }^{7}$

\begin{abstract}
Background: Mental health has become a major public health issue worldwide. Biological and epidemiological studies suggest diet has a role in the prevention or cure of mental disorders. However, further research is required to elucidate the relationship between diet and mental health. This study aimed to investigate associations between dietary intake of nutrients (macronutrients, vitamins, calcium, and fatty acids) and food groups (fish, meat and chicken, dairy products, and vegetables) and mental health among middle-aged Japanese in cross-sectional and prospective studies.

Methods: In total, 9298 men and women that participated in two areas of the Japan Multi-Institutional Collaborative Cohort Study were eligible for analysis at the baseline (cross-sectional) survey. Of these, 4701 participants were followed for about 5 years and included in the follow-up (prospective) analysis. The 12-item General Health Questionnaire (GHQ) was used to assess participants' general mental health status over the past several weeks. The average intake of 46 foods over the past year was assessed by a validated food frequency questionnaire. We also evaluated lifestyle and medical factors using a self-administered questionnaire. A cross-sectional logistic regression analysis was performed to estimate odds ratios for a GHQ score $\geq 4$ (poor mental health) according to dietary intake of foods/nutrients at baseline. The prospective study used baseline dietary and lifestyle factors and GHQ scores at follow-up.
\end{abstract}

Results: The cross-sectional logistic regression analysis showed vegetables, protein, calcium, vitamin D, carotene and n-3 highly-polyunsaturated fatty acids were inversely associated with a GHQ score $\geq 4$. On the other hand, mono-unsaturated fatty acids showed a positive association with higher $\mathrm{GHQ}$ score. The prospective logistic regression analysis found dairy products, calcium, vitamin $B_{2}$, and saturated fatty acids were inversely correlated with a GHQ score $\geq 4$. Calcium was associated with GHQ scores in both the cross-sectional and follow-up studies. In the follow-up study, the multivariableadjusted odds ratio for a GHQ score $\geq 4$ was 0.71 (95\% confidence interval, $0.55-0.92$ ) for the highest versus lowest quartiles of calorie-adjusted dietary calcium intake.

Conclusion: Consuming particular nutrients and foods, especially calcium and dairy products, may lead to better mental health in Japanese adults.

Keywords: Mental health, General Health Questionnaire, Nutrition, Food, Calcium, Japanese, Cohort studies

\footnotetext{
* Correspondence: choda.naoki@b.mbox.nagoya-u.ac.jp

'Department of Preventive Medicine, Nagoya University Graduate School of

Medicine, Nagoya, Aichi 466-8550, Japan

Full list of author information is available at the end of the article
}

(c) The Author(s). 2020 Open Access This article is distributed under the terms of the Creative Commons Attribution 4.0 International License (http://creativecommons.org/licenses/by/4.0/), which permits unrestricted use, distribution, and reproduction in any medium, provided you give appropriate credit to the original author(s) and the source, provide a link to the Creative Commons license, and indicate if changes were made. The Creative Commons Public Domain Dedication waiver (http://creativecommons.org/publicdomain/zero/1.0/) applies to the data made available in this article, unless otherwise stated. 


\section{Background}

Mental health has become a major public health issue worldwide. It has been estimated that mental disorders (represented by depressive and anxiety disorders) account for $13 \%$ of the global burden of disease in terms of disability-adjusted life-years, which is equivalent to cardiovascular and circulatory diseases [1]. Mental disorders are also common in Japan, with the prevalence of common mental disorders (e.g. major depression, specific phobia, and alcohol abuse/dependence) reported to be $8.8 \%$ [2]. Furthermore, a patient survey conducted by the Japan Ministry of Health, Labour and Welfare showed the number of patients with mental disorders in Japan had almost doubled in the last two decades, from 2 million in 2000 to 4 million in 2015.

It is important to address the increasing prevalence of mental disorders because these disorders reduce people's quality of life, worsen many medical illnesses, promote disability, and increase mortality [3]. Furthermore, mental disorders can lead to other social problems, such as loss of productivity at work, suicide, or criminal behavior [4-6]. Therefore, mental disorders impose a major burden on individuals and society.

There has been a steady increase in biological and epidemiological studies investigating the relationships between diet and mental health [7, 8]. It has been suggested that various dietary patterns, foods, and nutrients may affect the onset, prolongation, and severity of mental disorders. For example, a positive association was found between Western dietary patterns and mental disorders such as depression and anxiety, whereas Mediterranean dietary patterns were reported to have protective effects $[7,9,10]$. High intakes of fruit, vegetables, fish, poultry, dairy products, unprocessed meat, and whole grains have been associated with a reduced depression risk $[8,11,12]$. Many nutrients are suggested to be effective against depression, including calcium, magnesium, zinc, folate, vitamins $D$ and $B_{12}$, and $n-3$ polyunsaturated fatty acids (PUFA) $[8,13]$.

Although diet may have a role in the prevention or cure of mental disorders, especially depression, further research is needed to elucidate the diet-mental health relationship. Some challenges and unclear points have been highlighted. First, although prospective (longitudinal) studies can reflect causal relationships, there are fewer prospective reports available than cross-sectional studies. Second, from the perspective of explanatory variables, analyzing dietary patterns or foods tells us how/ what to eat; however, key components remain unclear, which may be detected by analysis of nutrients. Finally, even though the 12-item General Health Questionnaire (GHQ-12) is widely used for screening common and general mental disorders not limited to specific diseases [14], few reports have used the GHQ-12 compared with other scales specific to depression, such as the Center for Epidemiological Studies Depression Scale. Therefore, this study aimed to explore the associations between dietary intake of food groups/nutrients and general mental health assessed with the GHQ-12 in a Japanese population, using both cross-sectional and prospective studies. The food groups included fish, meat and chicken, dairy products, and vegetables. We also investigated three macronutrients, vitamins, calcium, and fatty acids.

\section{Methods}

This study used the STROBE-Nut as a reporting guideline (Additional file 1).

\section{The Japan Multi-Institutional Collaborative Cohort (J- MICC) Study}

The J-MICC Study is a cohort study that aimed to elucidate the interactions among genotypes, lifestyles, and lifestyle-related diseases, especially cancer [15]. The JMICC Study was launched in 2005 and plans to follow participants until 2025. We conducted the present analyses in two areas covered by the J-MICC Study: the Daiko Study and the Shizuoka area, because GHQ-12 data were available in these two areas.

\section{Participants}

In the Daiko Study, Nagoya city residents aged 35-69 years were invited to participate in the baseline survey between 2008 and 2010 through posted leaflets [16]. When the dataset was fixed for analysis in May 2015, 21 of the 5174 participants had withdrawn from the study or were ineligible to participate; therefore, 5153 men and women were available for the baseline analyses. Approximately 5 years later (2013-2016), 3543 participants (68.8\%) took part in a second (follow-up) survey.

In the Shizuoka area of the J-MICC Study, participants were residents aged 35-69 years who attended the Seirei Preventive Health Care Center in Hamamatsu for a health check-up [17]. Among 13,740 examinees that met the eligibility criteria, 5040 (36.7\%) were enrolled between 2006 and 2007. When the dataset was fixed for analysis in May 2015, 32 participants had withdrawn from the study or were ineligible to participate, leaving 5008 available for baseline analyses. Approximately 6 years later (20122013), 3746 participants $(74.8 \%)$ responded to the second (follow-up) survey.

In total, 9298 participants met the eligibility criteria and were included in the baseline analyses. We followed 6697 participants whose GHQ score was < 4 at baseline; 4701 were included in the follow-up study after excluding dropouts and ineligible participants. In the baseline and follow-up studies, we excluded participants who had missing data on GHQ score or covariates, those who reported extreme total energy intake (outside the mean \pm 3 standard deviations [SD]) and those who regularly took 
medication that may affect the central nervous system. The flowchart of the study protocol is presented in Fig. 1.

\section{Mental health assessment}

We used the GHQ-12 to assess participants' general mental health status over the past several weeks. The GHQ-12 is a widely used scale for measuring general psychological wellbeing. According to the factor structure analysis in a Japanese adult population, the GHQ-12 is a valid scale that mainly produces psychological distress and social dysfunction factors [18]. Each GHQ-12 item describes a particular behavior or symptom. There are four possible responses to each item: not at all, no more than usual, rather more than usual, or much more than usual. The first and second responses are scored as zero, and the third and fourth responses are scored as 1 . The individual item scores are summed, giving a total score from 0 to 12 . A GHQ-12 score $\geq 4$ is considered to reflect poor mental health [19].

\section{Dietary assessment}

The average intake of 46 foods over the past year was assessed with a validated short food frequency questionnaire (FFQ), as described in previous reports [20-23]. For daily amounts of three staple foods (rice, bread, and noodles), questions were asked about the portion/serving size and frequency of consumption (six categories: almost none, 1-3 times/month, 1-2 times/week, 3-4 times/week, 5-6 times/week, and daily). For the other 43 dietary items, we only investigated intake frequency (eight categories: almost none, 1-3 times/month, 1-2 times/week, 3-4 times/week, 5-6 times/week, 1 time/ day, 2 times/day, and $\geq 3$ times/day) [22]. The dietary intakes of foods/nutrients were estimated using a program developed and validated at the Department of Public Health, Nagoya City University School of Medicine, based on the standard tables of food composition in Japan (fifth revised edition) [22, 24].

\section{Other variables}

We evaluated lifestyle factors (smoking habits, alcohol consumption, sleeping time, physical activity, and eating breakfast), educational attainment, employment status and medicine intake using a self-administered questionnaire [15]. Employment status was dichotomized based on participants' status at baseline (working, not working). Smoking habits and alcohol consumption were both divided into five categories (for smoking: never, former, current smoker of $<20$ cigarettes/day, 20-39 cigarettes/day, $\geq 40$ cigarettes/day; for drinking: never, former, current drinker of < $150 \mathrm{~g} /$ week, $150-300 \mathrm{~g} /$ week, and $\geq 300 \mathrm{~g} /$ week). Participants were defined as current drinkers if they drank once a month or more frequently. We also asked how many hours participants slept per day and how many times they ate breakfast per week. Physical activity was assessed in terms of metabolic equivalents (METs) of leisure-time activity, as reported elsewhere [25]. Participants' highest educational

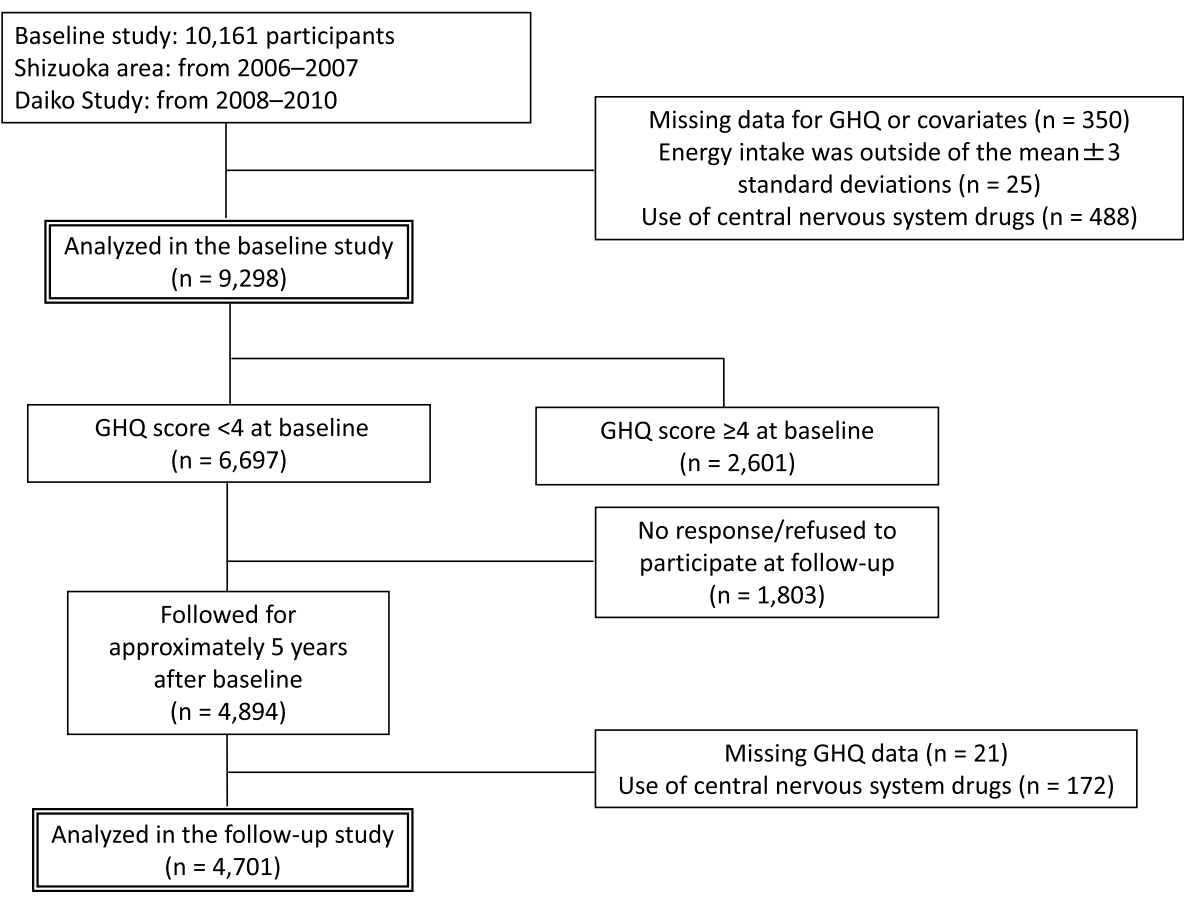

Fig. 1 Flowchart of the study protocol. GHQ: General Health Questionnaire 
attainment was also covered in the baseline survey. Educational attainment was classified using three groups: primary/secondary education, tertiary education (undergraduate/graduate school), and others (college of technology, vocational school, community college). For medicine intake, we asked whether participants were regularly taking six types of medicine, including sleeping medication. In addition, they were requested to list any medicines they regularly took that were not classified in these six categories. We checked the intakes of sleeping drugs, anti-anxiety agents, anti-depressant drugs, and anti-psychotic drugs. We did not consider other central nervous system drugs, such as anti-epileptic agents and anti-dementia drugs.

\section{Statistical analysis}

Differences in baseline characteristics between participants with a GHQ score $<4$ and those with a GHQ score $\geq 4$ were assessed using $t$-tests (for continuous variables) or $\chi^{2}$ tests (for categorical variables). Differences in food or nutrient intakes between the two groups were assessed with the Mann-Whitney test (foods) or $t$-tests after logarithmic conversion (nutrients).

We estimated the odds ratio (OR) for a GHQ score $\geq 4$ according to intakes of foods and nutrients using multivariable logistic regression analyses. Consumption of fish, meat, chicken, dairy products, and vegetables was energyadjusted by dividing total energy intake and was categorized into quartiles. Similarly, we included quartiles of energy-adjusted intakes into the logistic models for: protein; fat; carbohydrate; calcium; vitamins $\mathrm{B}_{1}, \mathrm{~B}_{2}$, and $\mathrm{D}$; $\beta$ carotene; saturated fatty acids (SFA); monounsaturated fatty acids (MUFA); n-6 PUFA; n-3 PUFA, and n-3 highly-polyunsaturated fatty acids ( $n-3$ HUFA). All values for foods, nutrients, and other covariates were measured at baseline. Confounding factors adjusted for (as categorical variables) were: study area (Daiko or Shizuoka), sex (men or women), current employment status (employed or not employed), current smoking status (five categories), and current drinking status (five categories). Age (years), sleeping time (h/day), leisure time exercise (METs h/day), eating breakfast (times/week), and total energy ( $\mathrm{kcal} /$ day) were adjusted as continuous variables.

In the prospective study, we followed those whose GHQ score was $<4$ at baseline. The OR for a GHQ score $\geq 4$ at the follow-up study by baseline intakes of foods and nutrients was estimated by using a logistic model adjusting for the same covariates as in the cross-sectional study. Trends in associations ( $P$-trend) across quartiles of food group or nutrient intake were assessed using multivariable logistic regression analysis, with median values assigned to each quartile category.

For sensitivity analyses, we analyzed data including participants taking central nervous system drugs. We also calculated the ORs for calcium and SFA by further adjusting for dairy products in the prospective study, and assessed the influence of further adjustment for educational attainment. In the prospective study, we added analysis without excluding those with GHQ score $\geq 4$ at baseline. Furthermore, to consider the changes in calcium intake from baseline to follow-up, we created four groups using the median value of the calorie-adjusted calcium intake at baseline and follow-up as cutoff values: maintained high intake, increased intake, decreased intake, and maintained low intake (reference). The OR for GHQ score $\geq 4$ at follow-up was calculated after adjustment for the same covariates as those in the abovementioned model for the cross-sectional study.

In logistic regression analysis, it has been suggested that the number of events per independent variable should be 10 or greater to avoid bias in the estimation of the regression coefficients [26]. The value was 216 at baseline and 65 at follow-up. We could include therefore many more participants in the analyses.

All analyses used SPSS version 24.0 for Windows (IBM, Armonk, NY) and SAS version 9.1 for Windows (SAS Institute, Cary, NC).

\section{Results}

Of the 9298 eligible participants at baseline, 2601 $(27.8 \%)$ showed poor mental health (GHQ score $\geq 4$ ) (Table 1). The 6697 participants with a GHQ score $<4$ at baseline were followed, and $4701(70.2 \%)$ were analyzed in the follow-up study after excluding dropouts $(n=1803)$ and ineligible participants $(n=193)$. In total, 783 of the 4701 participants (16.7\%) showed poor mental health at follow-up (Table 2).

Approximately half of the participants at both baseline and follow-up were women. At both measurements, the proportion of males, proportion of elder people, sleeping time, and leisure-time exercise were significantly lower among participants with a GHQ score $\geq 4$ than those with a GHQ score $<4$. Tables 3 and 4 show food and nutrient intakes at baseline and follow-up, respectively. Intakes of fish, calcium, vitamins $B_{2}$ and $D$, and $n-3$ HUFA were significantly lower in those with a GHQ score $\geq 4$ than those with a GHQ score $<4$ at both baseline and follow-up. In contrast, those with a GHQ score $\geq 4$ consumed significantly more fat, MUFA, and n-6 PUFA than those with a GHQ-12 score $<4$.

Table 5 shows the results of the cross-sectional multiple logistic regression analyses using baseline data. We observed inverse associations between a GHQ score $\geq 4$ and protein, calcium, vitamin D, carotene, and n-3 HUFA ( $P$ trend $<0.05$ ), whereas MUFA showed a positive correlation (Model 2). Vegetables demonstrated a significant inverse association and dairy products showed a marginally 
Table 1 Characteristics of participants at baseline $(n=9298)$

\begin{tabular}{|c|c|c|c|c|c|}
\hline \multirow[b]{2}{*}{ Categorical variables } & \multicolumn{2}{|c|}{ Participants with a GHQ score $\geq 4$} & \multicolumn{2}{|c|}{ Participants with a GHQ score $<4$} & \multirow[t]{2}{*}{$p^{a}$} \\
\hline & $n$ & $\%$ & $n$ & $\%$ & \\
\hline Number of participants & 2601 & & 6697 & & \\
\hline Area (Shizuoka) & 1084 & 41.7 & 3578 & 53.4 & $<0.001$ \\
\hline Sex (women) & 1543 & 59.3 & 3227 & 48.2 & $<0.001$ \\
\hline Current worker & 1996 & 76.7 & 4987 & 74.5 & 0.023 \\
\hline Smoking & & & & & 0.002 \\
\hline Never & 1623 & 62.4 & 3889 & 58.1 & \\
\hline Former & 619 & 23.8 & 1812 & 27.1 & \\
\hline Current $<20$ cigarettes/day & 178 & 6.8 & 496 & 7.4 & \\
\hline Current 20-39 cigarettes/day & 161 & 6.2 & 462 & 6.9 & \\
\hline Current $\geq 40$ cigarettes/day & 20 & 0.8 & 38 & 0.6 & \\
\hline Drinking & & & & & 0.001 \\
\hline Never & 1073 & 41.3 & 2720 & 40.6 & \\
\hline Former & 49 & 1.9 & 82 & 1.2 & \\
\hline Current $<150 \mathrm{~g} /$ week & 1026 & 39.4 & 2500 & 37.3 & \\
\hline Current $150-300 \mathrm{~g} /$ week & 260 & 10.0 & 812 & 12.1 & \\
\hline Current $\geq 300 \mathrm{~g} /$ week & 193 & 7.4 & 583 & 8.7 & \\
\hline Continuous variables & Mean & SD & Mean & SD & \\
\hline Age (years) & 50.1 & 9.1 & 52.9 & 9.5 & $<0.001$ \\
\hline Sleeping time (h/day) & 6.4 & 0.9 & 6.6 & 0.9 & $<0.001$ \\
\hline Leisure-time exercise (METs $\cdot h /$ day) & 1.6 & 2.6 & 2.0 & 2.9 & $<0.001$ \\
\hline Eating breakfast (times/week) & 6.3 & 1.6 & 6.5 & 1.4 & $<0.001$ \\
\hline
\end{tabular}

GHQ General Health Questionnaire, METs Metabolic equivalents, SD Standard deviation

${ }^{a}$ Categorical variables: $\mathrm{X}^{2}$ test; continuous variables: $t$-test

insignificant negative correlation with a GHQ score $\geq 4$ $(P$-trend $=0.059)$.

Table 6 summarizes the result of the prospective multiple logistic regression analyses using follow-up data. Dairy products, calcium, vitamin $B_{2}$, and SFA showed inverse associations $(P$-trend $<0.05)$ with a GHQ score $\geq 4$, even after adjustment for covariates (Model 2). Calcium showed an association in both the cross-sectional and prospective studies. The multivariable-adjusted OR for a GHQ score $\geq$ 4 was 0.71 (95\% confidence interval [CI], 0.55-0.92) in the highest versus lowest quartiles of calorie-adjusted dietary calcium intake at follow-up (Table 6).

To check the role of selective drop-out of participants during follow-up, we examined baseline characteristics of participants with GHQ scores $<4$ at baseline (Additional file 2: Table S1). Compared with participants with GHQ scores $<3$ at baseline, individuals whose GHQ score was 3 at baseline were more likely to drop out.

Participants might have changed their eating habits during the follow-up period; however, the mean, SD, and quartiles at baseline (Additional file 3: Table S2) did not notably differ from those at follow-up (Additional file 4: Table S3). In addition, Pearson's correlation coefficients between baseline and follow-up were 0.50 or above for most nutrients (Additional file 4: Table S3).

As a sensitivity analysis, we calculated the OR of calcium and SFA by adjusting for dairy products in the prospective study. The $P$ values for trends for calcium and SFA became insignificant after this further adjustment (Additional file 5: Table S4).

In the prospective study, we also analyzed the data without excluding those with GHQ score $\geq 4$ at baseline (Additional file 6: Table S5). The overall findings were essentially unchanged from those in Table 6 . Dairy products, calcium, vitamin $B_{2}$, and SFA showed negative associations, and $P s$ for trends became smaller. The main difference was that n-3 PUFA showed a significant positive association with GHQ score.

We also conducted an analysis to consider the changes in calcium intake between baseline and follow-up. The multivariable-adjusted OR for a GHQ score $\geq 4$ for maintained high calcium intake (number of subjects with GHQ $\geq 4 /$ total number; $274 / 1757$ ) versus maintained low calcium intake (308/1770) was 0.78 (95\% CI, 0.63-0.97). The OR for increased calcium intake (96/580) or decreased calcium intake (105/594) versus maintained low calcium 
Table 2 Participants' (baseline) characteristics at follow-up $(n=4701)$

\begin{tabular}{|c|c|c|c|c|c|}
\hline \multirow[b]{2}{*}{ Categorical variables } & \multicolumn{2}{|c|}{ Participants with a GHQ score $\geq 4$} & \multicolumn{2}{|c|}{ Participants with a GHQ score $<4$} & \multirow[t]{2}{*}{$p^{a}$} \\
\hline & $n$ & $\%$ & $n$ & $\%$ & \\
\hline Number of participants & 783 & & 3918 & & \\
\hline Area (Shizuoka) & 433 & 55.3 & 2173 & 55.5 & 0.934 \\
\hline Sex (women) & 432 & 55.2 & 1805 & 46.1 & $<0.001$ \\
\hline Current worker & 609 & 77.8 & 2918 & 74.5 & 0.051 \\
\hline Smoking & & & & & 0.047 \\
\hline Never & 496 & 63.3 & 2285 & 58.3 & \\
\hline Former & 186 & 23.8 & 1123 & 28.7 & \\
\hline Current $<20$ cigarettes/day & 47 & 6.0 & 266 & 6.8 & \\
\hline Current 20-39 cigarettes/day & 50 & 6.4 & 229 & 5.8 & \\
\hline Current $\geq 40$ cigarettes/day & 4 & 0.5 & 15 & 0.4 & \\
\hline Drinking & & & & & 0.21 \\
\hline Never & 349 & 44.6 & 1575 & 40.2 & \\
\hline Former & 9 & 1.1 & 42 & 1.1 & \\
\hline Current $<150 \mathrm{~g} /$ week & 283 & 36.1 & 1498 & 38.2 & \\
\hline Current $150-300 \mathrm{~g} /$ week & 87 & 11.1 & 475 & 12.1 & \\
\hline Current $\geq 300 \mathrm{~g} /$ week & 55 & 7.0 & 328 & 8.4 & \\
\hline Continuous variables & Mean & SD & Mean & SD & \\
\hline Age (years) & 50.2 & 9.1 & 54.0 & 9.1 & $<0.001$ \\
\hline Sleeping time (h/day) & 6.5 & 0.9 & 6.7 & 0.9 & $<0.001$ \\
\hline Leisure-time exercise (METs • h/day) & 1.8 & 2.5 & 2.2 & 3.0 & $<0.001$ \\
\hline Eating breakfast (times/week) & 6.5 & 1.3 & 6.6 & 1.3 & 0.168 \\
\hline
\end{tabular}

GHQ General Health Questionnaire, METs Metabolic equivalents, SD Standard deviation

${ }^{a}$ Categorical variables: $\mathrm{X}^{2}$ test; continuous variables: $t$-test

intake was not statistically significant. The overall findings were not substantially altered when we included participants who were taking central nervous system drugs at baseline or follow-up (data not shown). In addition, further adjustment for educational attainment did not essentially change the findings.

\section{Discussion}

In the present cross-sectional and prospective studies, intakes of several foods and nutrients were inversely associated with high GHQ scores in Japanese adults. Protein showed a significant inverse correlation in the cross-sectional study and a negative association, though with an insignificant linear trend, in the follow-up study. To our knowledge, no previous clinical study has reported an association between dietary intakes of protein and mood in detail. However, protein may be beneficial for mood because tryptophan, an amino acid, is converted to serotonin that plays an important role in mood alleviation, satiety, and sleep regulation [27].

Calcium showed an inverse association with poor mental health both in the cross-sectional and prospective studies. Several investigations have reported similar associations between calcium and depression. A previous meta-analysis reported a pooled relative risk for depression of 0.66 (95\% $\mathrm{CI}, 0.42-1.02$ ) when comparing the highest and lowest intakes [28]. Because that meta-analysis was based on crosssectional studies, our prospective findings may be meaningful for further understanding the effect of calcium on mood. The biological mechanism underlying the influence of calcium may be activation of tryptophan hydroxylase in serotonin synthesis [29]. However, care is needed with calcium supplementation, as it may be a risk factor for vascular disease [30]. Consistent adverse effects on cardiovascular health have not demonstrated for dietary calcium [31]; therefore, obtaining calcium from the diet rather than supplements should be encouraged.

In our study, the $P$-trend for the inverse correlation with vitamin $B_{2}$ was significant at follow-up and marginally significant at baseline. Some previous reports have also suggested an association between vitamin $B_{2}$ and mental health. Vitamins $B_{12}, B_{6}$, and $B_{2}$ may slow the progression of cognitive decline and possibly reduce the risk of depression in ageing [32]. In addition, low intakes of B-vitamins have been related to poor adolescent mental health and behavior [33]. 
Table 3 Daily intake of food groups and nutrients among participants at baseline $(n=9298)$

\begin{tabular}{|c|c|c|c|c|c|}
\hline \multirow[t]{2}{*}{ Continuous variables } & \multicolumn{2}{|c|}{ Participants with a GHQ score $\geq 4$} & \multicolumn{2}{|c|}{ Participants with a GHQ score $<4$} & \multirow[b]{2}{*}{$p^{a}$} \\
\hline & Mean & SD & Mean & SD & \\
\hline \multicolumn{6}{|l|}{ Food groups (g) } \\
\hline Fish & 46.0 & 24.8 & 50.2 & 26.9 & $<0.001$ \\
\hline Meat and chicken & 38.3 & 21.7 & 37.2 & 21.6 & 0.006 \\
\hline Dairy products & 123.2 & 104.5 & 126.4 & 105.3 & 0.147 \\
\hline Vegetables & 132.9 & 77.9 & 136.9 & 78.7 & 0.012 \\
\hline \multicolumn{6}{|l|}{ Nutrients } \\
\hline Energy (kcal) & 1667 & 330 & 1718 & 338 & $<0.001$ \\
\hline Protein (g) & 51.7 & 10.2 & 53.2 & 10.7 & $<0.001$ \\
\hline Fat (g) & 44.5 & 10.6 & 43.7 & 10.8 & 0.001 \\
\hline Carbohydrate (g) & 232 & 60 & 242 & 62 & $<0.001$ \\
\hline Calcium (mg) & 510 & 141 & 523 & 143 & $<0.001$ \\
\hline Vitamin $B_{1}(\mathrm{mg})$ & 0.654 & 0.081 & 0.652 & 0.086 & 0.192 \\
\hline Vitamin $B_{2}(\mathrm{mg})$ & 1.08 & 0.25 & 1.10 & 0.25 & $<0.001$ \\
\hline Vitamin D $(\mu \mathrm{g})$ & 6.69 & 2.84 & 7.30 & 3.20 & $<0.001$ \\
\hline Carotene $(\mu \mathrm{g})$ & 3113 & 1381 & 3170 & 1334 & 0.009 \\
\hline Saturated fatty acids (g) & 11.41 & 2.67 & 11.36 & 2.70 & 0.409 \\
\hline Monounsaturated fatty acids (g) & 16.40 & 3.84 & 16.09 & 3.81 & $<0.001$ \\
\hline n-6 polyunsaturated fatty acids (g) & 11.07 & 2.90 & 10.91 & 2.87 & 0.012 \\
\hline n-3 polyunsaturated fatty acids (g) & 2.22 & 0.53 & 2.23 & 0.55 & 0.250 \\
\hline n-3 highly-polyunsaturated fatty acids (g) & 0.664 & 0.282 & 0.720 & 0.318 & $<0.001$ \\
\hline
\end{tabular}

GHQ General Health Questionnaire, SD Standard deviation. ${ }^{a}$ Food groups: Mann-Whitney test; nutrients: $t$-test after logarithmic transformation

Vitamin D intake has been associated with a lower risk for depression [8]. However, the association in our cross-sectional study might have been due to a reverse causal relationship, as no significant association was observed in the prospective study. Supplementation of $\beta$-carotene has been reported to reduce patients' anxiety and depression scores [34]. However, in our study, carotene showed an inverse association in the cross-sectional study but not in the prospective study.

Increasing evidence from observational studies and randomized placebo-controlled trials regarding fatty acids suggests that n-3 PUFA have ameliorating effects on mood disorders [35]. In laboratory experiments, n-3 PUFA exerted beneficial effects on moods through neuroendocrine modulation or anti-inflammatory effects [36]. However, in our cross-sectional study, n-3 PUFA showed significantly lower $\mathrm{OR}$ in the second quartile, and n-3 HUFA in the fourth quartile, and the $P$-trend was only significant for n-3 HUFA. In addition, these associations were not found in the prospective study, meaning the association in the cross-sectional study might have resulted from reverse causality. These unclear associations may be explained by high intakes of n3 PUFA in Japanese people [37]. A dose-response metaanalysis revealed a J-shaped association with the lowest risk for depression at $1.8 \mathrm{~g} / \mathrm{d}$ intake of $\mathrm{n}-3$ PUFA [38]. The average daily intake of $n-3$ PUFA in Japanese men and women aged $\geq 20$ years was reported as $2.47 \mathrm{~g}$ and $2.08 \mathrm{~g}$, respectively [39]. In addition, a prospective cohort study in Japanese older adults showed the association with depression was significant; the hazard ratio was lowest in the second quartile for eicosapentaenoic acid and in the third quartile for docosapentaenoic acid, but not significant for total n-3 PUFA [40]. Each component of n-3 PUFA may have maximum effects at different levels and the total effects may be unclear. We could not estimate intakes of individual fatty acids among n-3 PUFA with the FFQ used in this study.

A previous cohort study indicated weak inverse associations between MUFA and depression [41]. MUFA showed a positive association with poor mental health in the present cross-sectional study, but this relationship was not observed in the prospective study. The $P$-trend for SFA was also significant in the prospective study and marginally significant in the cross-sectional study. To our knowledge, there is little evidence to indicate beneficial effects of SFA on mood. The association with SFA might be explained by the intake of dairy products, as no significant association was observed after adjustment for dairy products (Additional file 5: Table S4). 
Table 4 Daily intake of food groups and nutrients at baseline among participants at follow-up $(n=4701)$

\begin{tabular}{|c|c|c|c|c|c|}
\hline \multirow[t]{2}{*}{ Continuous variables } & \multicolumn{2}{|c|}{ Participants with a GHQ score $\geq 4$} & \multicolumn{2}{|c|}{ Participants with a GHQ score $<4$} & \multirow[b]{2}{*}{$p^{a}$} \\
\hline & Mean & SD & Mean & SD & \\
\hline \multicolumn{6}{|l|}{ Food groups (g) } \\
\hline Fish & 49.9 & 31.0 & 50.9 & 25.8 & 0.009 \\
\hline Meat and chicken & 38.9 & 25.3 & 36.9 & 21.3 & 0.080 \\
\hline Dairy products & 125.3 & 109.1 & 132.2 & 107.2 & 0.023 \\
\hline Vegetables & 141.9 & 78.2 & 138.5 & 79.4 & 0.136 \\
\hline \multicolumn{6}{|l|}{ Nutrients } \\
\hline Energy (kcal) & 1715 & 350 & 1727 & 327 & 0.193 \\
\hline Protein (g) & 53.5 & 12.0 & 53.5 & 10.3 & 0.546 \\
\hline Fat (g) & 45.0 & 11.8 & 43.8 & 10.6 & 0.013 \\
\hline Carbohydrate (g) & 241 & 64 & 244 & 61 & 0.131 \\
\hline Calcium (mg) & 521 & 148 & 532 & 145 & 0.038 \\
\hline Vitamin $B_{1}(\mathrm{mg})$ & 0.656 & 0.098 & 0.651 & 0.083 & 0.232 \\
\hline Vitamin $B_{2}(\mathrm{mg})$ & 1.10 & 0.25 & 1.12 & 0.25 & 0.006 \\
\hline Vitamin D $(\mu \mathrm{g})$ & 7.22 & 3.60 & 7.41 & 3.15 & 0.019 \\
\hline Carotene $(\mu \mathrm{g})$ & 3257 & 1394 & 3197 & 1351 & 0.244 \\
\hline Saturated fatty acids (g) & 11.48 & 3.01 & 11.43 & 2.69 & 0.997 \\
\hline Monounsaturated fatty acids (g) & 16.58 & 4.16 & 16.05 & 3.76 & 0.001 \\
\hline n-6 polyunsaturated fatty acids (g) & 11.32 & 3.03 & 10.90 & 2.83 & $<0.001$ \\
\hline n-3 polyunsaturated fatty acids (g) & 2.29 & 0.61 & 2.24 & 0.54 & 0.060 \\
\hline n-3 highly-polyunsaturated fatty acids (g) & 0.714 & 0.364 & 0.730 & 0.314 & 0.032 \\
\hline
\end{tabular}

GHQ General Health Questionnaire, SD Standard deviation. ${ }^{a}$ Food groups: Mann-Whitney test; nutrients: $t$-test after logarithmic transformation

Consumption of dairy products was inversely associated with a GHQ score $\geq 4$ in the prospective study and marginally significant in the cross-sectional study. Dairy products contain minerals (e.g., calcium) as well as many vitamins (e.g., vitamins $\mathrm{A}, \mathrm{D}, \mathrm{B}_{2}$, and $\mathrm{B}_{12}$ ), and protein. The association for calcium in the prospective study was attenuated by adjustment for intake of dairy products (Additional file 5: Table S4). This suggests that the effect of dairy products may be partly related to calcium intake or vice versa. Yogurt also contains probiotics, some of which have been reported to be beneficial to depression or anxiety disorders [8]. Some studies have related dairy products to depressive symptoms, but the results were not consistent [42]. This discrepancy may be attributable to different types of dairy products. Interestingly, a previous cross-sectional study involving Japanese adults showed consumption of low-fat dairy (but not whole-fat dairy) was inversely associated with depressive symptoms [42]. Those authors hypothesized that trans-fatty acids in whole-fat milk may be detrimental to depression. However, high consumption of whole-fat yogurt was related to a lower risk for depression in women in a cohort study; the study group speculated that linoleic acid in whole-fat yogurt may have beneficial effects [43]. We did not differentiate low-fat from whole-fat dairy in the FFQ, and therefore could not address this issue.
In our cross-sectional study, vegetable intake showed an inverse association with a GHQ score $\geq 4$. This finding may be related to the inverse association between carotene and GHQ score $\geq 4$ in the cross-sectional study. Fish, which is rich in n-3 PUFA and protein, showed a somewhat inverse association in the cross-sectional study. A systematic review revealed consumption of fish and vegetables was associated with a somewhat lower incidence of depressive symptoms [9]. However, the reason why the association was not observed in the present prospective study is not clear.

The strength of this study was that it comprehensively examined associations of nutrients and foods with general psychological wellbeing in both cross-sectional and prospective studies and adjusted for several confounders. By analyzing both foods and nutrients, we may have successfully identified the types of foods that are beneficial, as well as key components for better mental health. A crosssectional study can be conducted in a larger population with greater statistical power than a prospective study. A prospective study can consider incidence and temporality of health problems, but there always is an issue of potential change in participants' lifestyles during follow-up. Therefore, the significant associations between nutrients (e.g., calcium, protein) and GHQ-12 score in both the cross- 
Table 5 Cross-sectional logistic regression analyses for the association between food/nutrient intake and GHQ-12 score

\begin{tabular}{|c|c|c|c|c|c|c|c|c|}
\hline \multirow{2}{*}{$\overline{\text { Food groups }}$} & & \multirow[t]{2}{*}{ Participants with GHQ score $\geq 4$ (n) } & \multicolumn{2}{|c|}{ Model $1(\mathrm{OR}, 95 \% \mathrm{Cl})^{\mathrm{a}}$} & \multirow[t]{2}{*}{$P$-trend } & \multicolumn{2}{|c|}{ Model $2(\mathrm{OR}, 95 \% \mathrm{Cl})^{\mathrm{b}}$} & \multirow[t]{2}{*}{ P-trend } \\
\hline & & & & & & & & \\
\hline \multirow[t]{4}{*}{ Fish } & Q1 (low) & 707 & 1 & (Ref.) & 0.064 & 1 & (Ref.) & 0.070 \\
\hline & Q2 & 701 & 0.98 & $(0.86-1.11)$ & & 0.97 & $(0.85-1.10)$ & \\
\hline & Q3 & 598 & 0.84 & $(0.74-0.96)$ & & 0.84 & $(0.73-0.96)$ & \\
\hline & Q4 (high) & 595 & 0.91 & $(0.79-1.04)$ & & 0.90 & $(0.79-1.04)$ & \\
\hline \multirow[t]{4}{*}{ Meat and chicken } & Q1 (low) & 564 & 1 & (Ref.) & 0.876 & 1 & (Ref.) & 0.977 \\
\hline & Q2 & 633 & 0.99 & $(0.86-1.13)$ & & 0.99 & $(0.87-1.14)$ & \\
\hline & Q3 & 683 & 1.01 & $(0.88-1.16)$ & & 1.01 & $(0.88-1.16)$ & \\
\hline & Q4 (high) & 721 & 1.00 & $(0.87-1.15)$ & & 1.00 & $(0.87-1.15)$ & \\
\hline \multirow[t]{4}{*}{ Dairy products } & Q1 (low) & 652 & 1 & (Ref.) & 0.011 & 1 & (Ref.) & 0.059 \\
\hline & Q2 & 647 & 0.97 & $(0.85-1.11)$ & & 0.99 & $(0.87-1.14)$ & \\
\hline & Q3 & 661 & 0.97 & $(0.85-1.11)$ & & 1.00 & $(0.87-1.14)$ & \\
\hline & Q4 (high) & 641 & 0.84 & $(0.74-0.96)$ & & 0.88 & $(0.77-1.01)$ & \\
\hline \multirow[t]{4}{*}{ Vegetables } & Q1 (low) & 660 & 1 & (Ref.) & 0.026 & 1 & (Ref.) & 0.045 \\
\hline & Q2 & 635 & 0.84 & $(0.74-0.96)$ & & 0.86 & $(0.75-0.98)$ & \\
\hline & Q3 & 662 & 0.85 & $(0.74-0.98)$ & & 0.87 & $(0.75-1.00)$ & \\
\hline & Q4 (high) & 644 & 0.82 & $(0.71-0.95)$ & & 0.83 & $(0.72-0.96)$ & \\
\hline \multicolumn{9}{|l|}{ Nutrients } \\
\hline \multirow[t]{4}{*}{ Protein } & Q1 (low) & 628 & 1 & (Ref.) & 0.002 & 1 & (Ref.) & 0.003 \\
\hline & Q2 & 662 & 0.95 & $(0.83-1.09)$ & & 0.94 & $(0.82-1.07)$ & \\
\hline & Q3 & 656 & 0.85 & $(0.74-0.97)$ & & 0.84 & $(0.73-0.97)$ & \\
\hline & Q4 (high) & 655 & 0.82 & $(0.71-0.94)$ & & 0.82 & $(0.71-0.95)$ & \\
\hline \multirow[t]{4}{*}{ Carbohydrate } & Q1 (low) & 542 & 1 & (Ref.) & 0.571 & 1 & (Ref.) & 0.996 \\
\hline & Q2 & 621 & 0.88 & $(0.78-1.00)$ & & 0.92 & $(0.80-1.05)$ & \\
\hline & Q3 & 688 & 0.85 & $(0.75-0.97)$ & & 0.88 & $(0.76-1.01)$ & \\
\hline & Q4 (high) & 750 & 1.00 & $(0.87-1.14)$ & & 1.04 & $(0.88-1.22)$ & \\
\hline \multirow[t]{4}{*}{ Fat } & Q1 (low) & 746 & 1 & (Ref.) & 0.641 & 1 & (Ref.) & 0.980 \\
\hline & Q2 & 663 & 1.02 & $(0.88-1.17)$ & & 0.99 & $(0.86-1.15)$ & \\
\hline & Q3 & 590 & 1.01 & $(0.88-1.17)$ & & 1.00 & $(0.86-1.16)$ & \\
\hline & Q4 (high) & 602 & 1.04 & $(0.89-1.21)$ & & 1.00 & $(0.85-1.17)$ & \\
\hline \multirow[t]{4}{*}{ Calcium } & Q1 (low) & 630 & 1 & (Ref.) & 0.005 & 1 & (Ref.) & 0.006 \\
\hline & Q2 & 668 & 0.98 & $(0.86-1.12)$ & & 0.94 & $(0.82-1.08)$ & \\
\hline & Q3 & 648 & 0.87 & $(0.76-1.00)$ & & 0.85 & $(0.74-0.99)$ & \\
\hline & Q4 (high) & 655 & 0.83 & $(0.72-0.96)$ & & 0.82 & $(0.70-0.95)$ & \\
\hline \multirow[t]{4}{*}{ Vitamin $B_{1}$} & Q1 (low) & 525 & 1 & (Ref.) & 0.430 & 1 & (Ref.) & 0.785 \\
\hline & Q2 & 642 & 1.09 & $(0.95-1.25)$ & & 1.07 & $(0.92-1.24)$ & \\
\hline & Q3 & 706 & 1.10 & $(0.94-1.27)$ & & 1.05 & $(0.88-1.24)$ & \\
\hline & Q4 (high) & 728 & 1.08 & $(0.93-1.26)$ & & 1.00 & $(0.82-1.22)$ & \\
\hline \multirow[t]{4}{*}{ Vitamin $B_{2}$} & Q1 (low) & 633 & 1 & (Ref.) & 0.138 & 1 & (Ref.) & 0.098 \\
\hline & Q2 & 625 & 0.91 & $(0.80-1.04)$ & & 0.90 & $(0.79-1.04)$ & \\
\hline & Q3 & 693 & 0.99 & $(0.86-1.13)$ & & 0.98 & $(0.84-1.13)$ & \\
\hline & Q4 (high) & 650 & 0.87 & $(0.76-1.01)$ & & 0.85 & $(0.73-1.00)$ & \\
\hline \multirow[t]{2}{*}{ Vitamin D } & Q1 (low) & 694 & 1 & (Ref.) & 0.008 & 1 & (Ref.) & 0.009 \\
\hline & Q2 & 719 & 0.98 & $(0.86-1.12)$ & & 0.95 & $(0.84-1.09)$ & \\
\hline
\end{tabular}


Table 5 Cross-sectional logistic regression analyses for the association between food/nutrient intake and GHQ-12 score (Continued)

\begin{tabular}{|c|c|c|c|c|c|c|c|c|}
\hline & \multirow[b]{2}{*}{ Q3 } & \multirow{2}{*}{$\begin{array}{l}\text { Participants with GHQ score } \geq 4 \text { (n) } \\
606\end{array}$} & \multicolumn{2}{|c|}{ Model $1(\mathrm{OR}, 95 \% \mathrm{Cl})^{\mathrm{a}}$} & \multirow[t]{2}{*}{$P$-trend } & \multicolumn{2}{|c|}{ Model $2(\mathrm{OR}, 95 \% \mathrm{Cl})^{\mathrm{b}}$} & \multirow[t]{2}{*}{$P$-trend } \\
\hline & & & 0.84 & $(0.73-0.96)$ & & 0.83 & $(0.72-0.95)$ & \\
\hline & Q4 (high) & 582 & 0.86 & $(0.75-0.99)$ & & 0.85 & $(0.74-0.98)$ & \\
\hline \multirow[t]{4}{*}{ Carotene } & Q1 (low) & 651 & 1 & (Ref.) & 0.010 & 1 & (Ref.) & 0.015 \\
\hline & Q2 & 654 & 0.87 & $(0.76-0.99)$ & & 0.86 & $(0.75-0.99)$ & \\
\hline & Q3 & 640 & 0.78 & $(0.68-0.90)$ & & 0.79 & $(0.68-0.91)$ & \\
\hline & Q4 (high) & 656 & 0.81 & $(0.70-0.93)$ & & 0.80 & $(0.69-0.94)$ & \\
\hline \multirow[t]{4}{*}{ SFA } & Q1 (low) & 563 & 1 & (Ref.) & 0.180 & 1 & (Ref.) & 0.097 \\
\hline & Q2 & 643 & 1.00 & $(0.87-1.15)$ & & 0.97 & $(0.84-1.12)$ & \\
\hline & Q3 & 672 & 0.92 & $(0.79-1.07)$ & & 0.88 & $(0.76-1.03)$ & \\
\hline & Q4 (high) & 722 & 0.92 & $(0.78-1.07)$ & & 0.88 & $(0.75-1.04)$ & \\
\hline \multirow[t]{4}{*}{ MUFA } & Q1 (low) & 518 & 1 & (Ref.) & 0.001 & 1 & (Ref.) & 0.019 \\
\hline & Q2 & 635 & 1.12 & $(0.97-1.29)$ & & 1.11 & $(0.96-1.28)$ & \\
\hline & Q3 & 678 & 1.11 & $(0.96-1.28)$ & & 1.10 & $(0.95-1.28)$ & \\
\hline & Q4 (high) & 770 & 1.28 & $(1.10-1.48)$ & & 1.22 & $(1.04-1.42)$ & \\
\hline \multirow[t]{4}{*}{ n-6 PUFA } & Q1 (low) & 546 & 1 & (Ref.) & 0.040 & 1 & (Ref.) & 0.130 \\
\hline & Q2 & 644 & 1.07 & $(0.93-1.22)$ & & 1.04 & $(0.91-1.20)$ & \\
\hline & Q3 & 660 & 1.02 & $(0.88-1.17)$ & & 1.00 & $(0.87-1.16)$ & \\
\hline & Q4 (high) & 751 & 1.17 & $(1.02-1.35)$ & & 1.13 & $(0.97-1.31)$ & \\
\hline \multirow[t]{4}{*}{ n-3 PUFA } & Q1 (low) & 614 & 1 & (Ref.) & 0.119 & 1 & (Ref.) & 0.434 \\
\hline & Q2 & 600 & 0.85 & $(0.74-0.97)$ & & 0.84 & $(0.73-0.96)$ & \\
\hline & Q3 & 668 & 0.95 & $(0.83-1.09)$ & & 0.91 & $(0.79-1.05)$ & \\
\hline & Q4 (high) & 719 & 1.05 & $(0.92-1.21)$ & & 1.00 & $(0.86-1.16)$ & \\
\hline \multirow[t]{4}{*}{ n-3 HUFA } & Q1 (low) & 687 & 1 & (Ref.) & 0.020 & 1 & (Ref.) & 0.018 \\
\hline & Q2 & 713 & 0.96 & $(0.85-1.10)$ & & 0.93 & $(0.81-1.06)$ & \\
\hline & Q3 & 616 & 0.88 & $(0.77-1.01)$ & & 0.87 & $(0.76-1.00)$ & \\
\hline & Q4 (high) & 585 & 0.86 & $(0.75-0.99)$ & & 0.85 & $(0.73-0.98)$ & \\
\hline
\end{tabular}

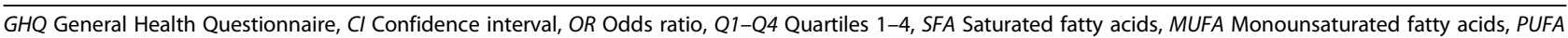
Polyunsaturated fatty acids, HUFA Highly-polyunsaturated fatty acids

Odds ratios shown by quartile of intake $(n=9298)$

${ }^{a}$ Model 1: adjusted for sex, age, and area

${ }^{\mathrm{b}}$ Model 2: adjusted for sex, age, area, employment, smoking, drinking, sleeping time, leisure time exercise, eating breakfast, and total energy

sectional and prospective studies suggest more likely relationships compared with findings from either study alone.

About half of the participants in our study were women, and both workers and non-workers were included in the sample. Among those aged 35-69 years at baseline, 23.4\% of men $(n=4528)$ and $32.3 \%$ of women $(n=4770)$ had a GHQ score $\geq 4$. Our study was conducted in only two geographical areas in Japan. However, a previous crosssectional community-based study in Kanazawa, Japan, reported a GHQ score $\geq 4$ in $24.2 \%$ of men $(n=4693$; mean age $51.6 \pm 19.5$ years $)$ and $32.0 \%$ of women $(n=5678$; mean age $52.4 \pm 19.4$ years) [44]. These percentages were close to ours, which suggests that our findings may be generalizable to the Japanese adult populations.

Several limitations in this study should be discussed. First, there is potential bias by selective dropout in the prospective study. Those who were more prone to mental health issues or who were actually experiencing mental health problems might have chosen not to participate in the follow-up study. Compared with participants whose GHQ score was $<3$ at baseline, participants whose GHQ score was 3 at baseline were more likely to drop out (Additional file 2: Table S1). Participants might have changed their eating habits during the 5 years of follow-up. However, any changes were not drastic, because all Pearson's correlation coefficients for nutrient intakes between the baseline and follow-up surveys were sufficiently high (Additional file 4: Table S3). Second, although we considered several covariates, unmeasured confounders might still exist. For example, genetic factors may play a role in the pathogenesis of depression [45] or anxiety disorders [46]. Among socioeconomic factors, we only adjusted for employment. However, further adjustment for educational attainment did not alter the findings. In addition, medication or 
Table 6 Prospective logistic regression analyses for association between food/nutrient intake and GHQ-12 score*

\begin{tabular}{|c|c|c|c|c|c|c|c|c|}
\hline \multirow{2}{*}{ Food groups } & & \multirow[t]{2}{*}{ Participants with GHQ score $\geq 4$ (n) } & \multicolumn{2}{|c|}{ Model $1(\mathrm{OR}, 95 \% \mathrm{Cl})^{\mathrm{a}}$} & \multirow[t]{2}{*}{$P$-trend } & \multicolumn{2}{|c|}{ Model $2(\mathrm{OR}, 95 \% \mathrm{Cl})^{\mathrm{b}}$} & \multirow[t]{2}{*}{$P$-trend } \\
\hline & & & & & & & & \\
\hline \multirow[t]{4}{*}{ Fish } & Q1 (low) & 211 & 1 & (Ref.) & 0.757 & 1 & (Ref.) & 0.886 \\
\hline & Q2 & 203 & 0.94 & $(0.75-1.16)$ & & 0.94 & $(0.75-1.16)$ & \\
\hline & Q3 & 194 & 0.97 & $(0.78-1.21)$ & & 0.98 & $(0.79-1.22)$ & \\
\hline & Q4 (high) & 175 & 0.95 & $(0.75-1.19)$ & & 0.97 & $(0.77-1.22)$ & \\
\hline \multirow[t]{4}{*}{ Meat and chicken } & Q1 (low) & 186 & 1 & (Ref.) & 0.345 & 1 & (Ref.) & 0.332 \\
\hline & Q2 & 191 & 0.84 & $(0.67-1.06)$ & & 0.87 & $(0.69-1.10)$ & \\
\hline & Q3 & 183 & 0.76 & $(0.60-0.96)$ & & 0.78 & $(0.61-0.98)$ & \\
\hline & Q4 (high) & 223 & 0.86 & $(0.68-1.08)$ & & 0.87 & $(0.69-1.09)$ & \\
\hline \multirow[t]{4}{*}{ Dairy products } & Q1 (low) & 208 & 1 & (Ref.) & 0.002 & 1 & (Ref.) & 0.002 \\
\hline & Q2 & 216 & 1.04 & $(0.84-1.29)$ & & 1.04 & $(0.83-1.29)$ & \\
\hline & Q3 & 176 & 0.75 & $(0.60-0.94)$ & & 0.74 & $(0.59-0.93)$ & \\
\hline & Q4 (high) & 183 & 0.75 & $(0.59-0.94)$ & & 0.75 & $(0.59-0.95)$ & \\
\hline \multirow[t]{4}{*}{ Vegetables } & Q1 (low) & 173 & 1 & (Ref.) & 0.362 & 1 & (Ref.) & 0.291 \\
\hline & Q2 & 212 & 1.17 & $(0.93-1.47)$ & & 1.20 & $(0.95-1.50)$ & \\
\hline & Q3 & 183 & 0.96 & $(0.76-1.22)$ & & 0.98 & $(0.77-1.25)$ & \\
\hline & Q4 (high) & 215 & 1.18 & $(0.92-1.51)$ & & 1.21 & $(0.95-1.55)$ & \\
\hline \multicolumn{9}{|l|}{ Nutrients } \\
\hline \multirow[t]{4}{*}{ Protein } & Q1 (low) & 210 & 1 & (Ref.) & 0.082 & 1 & (Ref.) & 0.128 \\
\hline & Q2 & 184 & 0.77 & $(0.62-0.96)$ & & 0.78 & $(0.62-0.98)$ & \\
\hline & Q3 & 181 & 0.69 & $(0.55-0.87)$ & & 0.69 & $(0.55-0.88)$ & \\
\hline & Q4 (high) & 208 & 0.81 & $(0.64-1.02)$ & & 0.83 & $(0.65-1.05)$ & \\
\hline \multirow[t]{4}{*}{ Carbohydrate } & Q1 (low) & 203 & 1 & (Ref.) & 0.307 & 1 & (Ref.) & 0.499 \\
\hline & Q2 & 205 & 1.07 & $(0.86-1.33)$ & & 1.07 & $(0.85-1.34)$ & \\
\hline & Q3 & 194 & 1.11 & $(0.89-1.39)$ & & 1.10 & $(0.86-1.40)$ & \\
\hline & Q4 (high) & 181 & 1.12 & $(0.88-1.42)$ & & 1.09 & $(0.83-1.43)$ & \\
\hline \multirow[t]{4}{*}{ Fat } & Q1 (low) & 175 & 1 & (Ref.) & 0.993 & 1 & (Ref.) & 0.601 \\
\hline & Q2 & 197 & 0.98 & $(0.78-1.24)$ & & 1.01 & $(0.80-1.28)$ & \\
\hline & Q3 & 185 & 0.79 & $(0.62-1.01)$ & & 0.82 & $(0.64-1.06)$ & \\
\hline & Q4 (high) & 226 & 0.92 & $(0.72-1.19)$ & & 0.96 & $(0.74-1.25)$ & \\
\hline \multirow[t]{4}{*}{ Calcium } & Q1 (low) & 216 & 1 & (Ref.) & 0.005 & 1 & (Ref.) & 0.019 \\
\hline & Q2 & 188 & 0.77 & $(0.62-0.97)$ & & 0.79 & $(0.63-0.99)$ & \\
\hline & Q3 & 191 & 0.73 & $(0.58-0.93)$ & & 0.75 & $(0.59-0.96)$ & \\
\hline & Q4 (high) & 188 & 0.68 & $(0.54-0.88)$ & & 0.71 & $(0.55-0.92)$ & \\
\hline \multirow[t]{4}{*}{ Vitamin $B_{1}$} & Q1 (low) & 177 & 1 & (Ref.) & 0.395 & 1 & (Ref.) & 0.878 \\
\hline & Q2 & 192 & 0.92 & $(0.73-1.17)$ & & 0.99 & $(0.77-1.28)$ & \\
\hline & Q3 & 199 & 0.83 & $(0.65-1.07)$ & & 0.91 & $(0.68-1.22)$ & \\
\hline & Q4 (high) & 215 & 0.89 & $(0.68-1.16)$ & & 1.02 & $(0.74-1.42)$ & \\
\hline \multirow[t]{4}{*}{ Vitamin $B_{2}$} & Q1 (low) & 213 & 1 & (Ref.) & 0.001 & 1 & (Ref.) & 0.007 \\
\hline & Q2 & 198 & 0.83 & $(0.66-1.03)$ & & 0.84 & $(0.67-1.05)$ & \\
\hline & Q3 & 188 & 0.72 & $(0.57-0.91)$ & & 0.73 & $(0.58-0.94)$ & \\
\hline & Q4 (high) & 184 & 0.68 & $(0.53-0.87)$ & & 0.70 & $(0.54-0.91)$ & \\
\hline \multirow[t]{2}{*}{ Vitamin D } & Q1 (low) & 206 & 1 & (Ref.) & 0.607 & 1 & (Ref.) & 0.832 \\
\hline & Q2 & 220 & 1.00 & $(0.81-1.25)$ & & 1.03 & $(0.83-1.28)$ & \\
\hline
\end{tabular}


Table 6 Prospective logistic regression analyses for association between food/nutrient intake and GHQ-12 score* (Continued)

\begin{tabular}{|c|c|c|c|c|c|c|c|c|}
\hline & \multirow[b]{2}{*}{ Q3 } & \multirow{2}{*}{$\begin{array}{l}\text { Participants with GHQ score } \geq 4 \text { (n) } \\
178\end{array}$} & \multicolumn{2}{|c|}{ Model $1(\mathrm{OR}, 95 \% \mathrm{Cl})^{\mathrm{a}}$} & \multirow[t]{2}{*}{$P$-trend } & \multicolumn{2}{|c|}{ Model $2(\mathrm{OR}, 95 \% \mathrm{Cl})^{\mathrm{b}}$} & \multirow[t]{2}{*}{$P$-trend } \\
\hline & & & 0.87 & $(0.69-1.09)$ & & 0.88 & $(0.70-1.11)$ & \\
\hline & Q4 (high) & 179 & 0.97 & $(0.77-1.23)$ & & 1.01 & $(0.80-1.28)$ & \\
\hline \multirow[t]{4}{*}{ Carotene } & Q1 (low) & 181 & 1 & (Ref.) & 0.863 & 1 & (Ref.) & 0.607 \\
\hline & Q2 & 210 & 1.06 & $(0.85-1.33)$ & & 1.12 & $(0.89-1.41)$ & \\
\hline & Q3 & 178 & 0.84 & $(0.66-1.07)$ & & 0.88 & $(0.69-1.13)$ & \\
\hline & Q4 (high) & 214 & 1.06 & $(0.82-1.36)$ & & 1.12 & $(0.86-1.44)$ & \\
\hline \multirow[t]{4}{*}{ SFA } & Q1 (low) & 189 & 1 & (Ref.) & 0.001 & 1 & (Ref.) & 0.003 \\
\hline & Q2 & 202 & 0.89 & $(0.71-1.12)$ & & 0.90 & $(0.71-1.14)$ & \\
\hline & Q3 & 195 & 0.73 & $(0.57-0.94)$ & & 0.76 & $(0.59-0.98)$ & \\
\hline & Q4 (high) & 197 & 0.65 & $(0.50-0.85)$ & & 0.68 & $(0.51-0.89)$ & \\
\hline \multirow[t]{4}{*}{ MUFA } & Q1 (low) & 171 & 1 & (Ref.) & 0.910 & 1 & (Ref.) & 0.688 \\
\hline & Q2 & 185 & 0.94 & $(0.74-1.19)$ & & 0.98 & $(0.77-1.25)$ & \\
\hline & Q3 & 209 & 0.98 & $(0.77-1.25)$ & & 1.05 & $(0.82-1.35)$ & \\
\hline & Q4 (high) & 218 & 0.96 & $(0.76-1.23)$ & & 1.04 & $(0.80-1.34)$ & \\
\hline \multirow[t]{4}{*}{ n-6 PUFA } & Q1 (low) & 168 & 1 & (Ref.) & 0.624 & 1 & (Ref.) & 0.361 \\
\hline & Q2 & 187 & 0.98 & $(0.77-1.23)$ & & 1.01 & $(0.80-1.29)$ & \\
\hline & Q3 & 204 & 0.99 & $(0.78-1.25)$ & & 1.03 & $(0.81-1.32)$ & \\
\hline & Q4 (high) & 224 & 1.05 & $(0.82-1.33)$ & & 1.11 & $(0.87-1.43)$ & \\
\hline \multirow[t]{4}{*}{ n-3 PUFA } & Q1 (low) & 174 & 1 & (Ref.) & 0.268 & 1 & (Ref.) & 0.093 \\
\hline & Q2 & 198 & 1.08 & $(0.86-1.36)$ & & 1.14 & $(0.90-1.44)$ & \\
\hline & Q3 & 192 & 0.99 & $(0.79-1.26)$ & & 1.06 & $(0.83-1.35)$ & \\
\hline & Q4 (high) & 219 & 1.16 & $(0.92-1.47)$ & & 1.26 & $(0.99-1.62)$ & \\
\hline \multirow[t]{4}{*}{ n-3 HUFA } & Q1 (low) & 212 & 1 & (Ref.) & 0.879 & 1 & (Ref.) & 0.853 \\
\hline & Q2 & 209 & 0.92 & $(0.74-1.15)$ & & 0.95 & $(0.76-1.19)$ & \\
\hline & Q3 & 175 & 0.83 & $(0.66-1.04)$ & & 0.85 & $(0.67-1.06)$ & \\
\hline & Q4 (high) & 187 & 0.99 & $(0.78-1.24)$ & & 1.04 & $(0.82-1.31)$ & \\
\hline
\end{tabular}

All variables (food and nutrient intakes and covariates) were measured at baseline

GHQ General Health Questionnaire, Cl Confidence interval, OR Odds ratio, Q1-Q4 Quartiles 1-4, SFA Saturated fatty acids, MUFA Monounsaturated fatty acids, PUFA Polyunsaturated fatty acids, HUFA Highly-polyunsaturated fatty acids

Odds ratios shown by quartile of intake $(n=4701)$

*Excludes those with a GHQ-12 score $\geq 4$ at baseline

${ }^{a}$ Model 1: adjusted for sex, age, and area

${ }^{\mathrm{b}}$ Model 2: adjusted for sex, age, area, employment, smoking, drinking, sleeping time, leisure time exercise, eating breakfast, and total energy

supplementation may be other residual confounders. At baseline, 1599 (17.2\%) participants reported regular use of any kind of vitamins or minerals. Furthermore, although we excluded participants who were taking medicine such as anti-depressant drugs, other medicines might have influenced mood [8]. Third, we could not assess the effects of possibly beneficial nutrients on mood (e.g., magnesium and vitamin $B_{12}$ ), because the FFQ had not been validated for those nutrients. The issue of multiple tests cannot be ruled out, because there were a lot of food groups and nutrients in both cross-sectional and prospective analyses. Our findings need to be confirmed by future studies. Finally, even though the GHQ-12 is widely used for screening common mental disorders [47], it is not a scale for specific mental disorders such as depression. There may be large heterogeneity among individuals with a GHQ score $\geq 4$. From another perspective, the use of GHQ score may have an advantage in assessing total impact of dietary factors on several common mental disorders, including depression [47].

Although the effects of diet on individual disorders may not be large, dietary intake may have considerable effects at a population level because of the high prevalence of mental distress as a whole. Diet is modifiable without severe adverse effects and changing dietary habits may be beneficial for prevention and treatment of mental disorders, although further studies are required to confirm our findings. 


\section{Conclusion}

The cross-sectional analysis showed intake of vegetables, protein, calcium, vitamin $\mathrm{D}$, carotene, and $\mathrm{n}-3$ HUFA were inversely associated with poor mental health, and intake of MUFA was positively associated. The prospective logistic regression analysis found dairy products, calcium, vitamin $\mathrm{B}_{2}$, and SFA were inversely correlated with poor mental health. Consuming adequate amounts of particular nutrients and foods, especially calcium and dairy products, may lead to better mental health in Japanese adults.

\section{Supplementary information}

Supplementary information accompanies this paper at https://doi.org/10. 1186/s12937-019-0515-6.

Additional file 1: STROBE Statement-checklist of items that should be included in reports of observational studies; items are boxed if the recommendations are satisfied.

Additional file 2: Table S1. Baseline characteristics of participants and those dropping out of the prospective study $(n=6697)$.

Additional file 3: Table S2. Cutoff values for quartiles of daily food and nutrient intakes at baseline.

Additional file 4: Table S3. Daily intakes of nutrients measured at follow-up $(n=4701)$.

Additional file 5: Table S4. Prospective logistic regression analyses of association between calcium/SFAs and GHQ-12 score with adjustment for dairy products.

Additional file 6: Table S5. Prospective logistic regression analyses for association between food/nutrient intakes and GHQ-12 score including those with GHQ-12 score $\geq 4$ at baseline.

\section{Abbreviations}

$\mathrm{Cl}$ : Confidence interval; FFQ: Food frequency questionnaire; GHQ: General Health Questionnaire; HUFA: Highly-polyunsaturated fatty acids; JMICC: Japan Multi-Institutional Collaborative Cohort Study; METs: Metabolic equivalents; MUFA: Monounsaturated fatty acids; OR: Odds ratio; PUFA: Polyunsaturated fatty acids; SD: Standard deviation; SFA: Saturated fatty acids

\section{Acknowledgments}

We thank Dr. Yatami Asai and all members of the Seirei Social Welfare Community for the recruitment and follow-up of participants in the Shizuoka part of the J-MICC Study. We also thank all the staff of the Department of Preventive Medicine, Nagoya University Graduate School of Medicine for the enrollment and follow-up of participants in the Daiko Study. We thank Audrey Holmes, MA and Melissa Leffler, MBA from Edanz Group (www.edanzediting.com/ac) for editing a draft of this manuscript.

\section{Author's contributions}

NC analyzed data and wrote the manuscript; KW designed and supervised this research and reviewed and edited the manuscript; MN and $\mathrm{NH}$ designed and supervised this research; NI and CG developed the food frequency questionnaire and program to estimate participants' dietary intakes. KM, YKadomatsu, MT, TS, YKubo, RO, SK, TT, AH, KT, and AM conducted the research (e.g., data acquisition). All authors reviewed and approved the final manuscript.

\section{Funding}

This study was supported by a JSPS KAKENHI Grant (No. 16H06277) and Grants-in-Aid for Scientific Research on Priority Areas (No. 17015018) and Innovative Areas (No. 221S0001) from the Japanese Ministry of Education, Culture, Sports, Science, and Technology.

\section{Availability of data and materials}

The datasets generated and analyzed during the present study are not publicly available because we did not obtain informed consent from participants for open use of individual data.

\section{Ethics approval and consent to participate}

The J-MICC Study, Daiko Study, and Shizuoka part of the J-MICC Study were approved by the Ethics Review Committee of the Nagoya University Graduate School of Medicine (approval numbers were 2010-0939, 2008-0618 and 2011-1248, respectively). All the participants provided written informed consent.

\section{Consent for publication}

The data analyzed in this study did not include personal information (i.e., name or address). All participants were adults.

\section{Competing interests}

The authors declare that they have no competing interests.

\section{Author details}

${ }^{1}$ Department of Preventive Medicine, Nagoya University Graduate School of Medicine, Nagoya, Aichi 466-8550, Japan. ²Department of Oral Epidemiology, Hiroshima University Graduate School of Biomedical and Health Sciences, Hiroshima 734-8553, Japan. ${ }^{3}$ Department of Nutrition, Faculty of Wellness, Shigakkan University, Obu, Aichi 474-8651, Japan. ${ }^{4}$ Department of Health and Nutrition, Nagoya Bunri University, Inazawa, Aichi 492-8520, Japan. ${ }^{5}$ Department of Public Health, Aichi Medical University School of Medicine, Nagakute, Aichi 480-1195, Japan. ${ }^{6}$ Seirei Preventive Health Care Center, Hamamatsu, Shizuoka 433-8105, Japan. ${ }^{7}$ Department of Healthcare Administration, Nagoya University Graduate School of Medicine, Nagoya, Aichi 466-8550, Japan.

Received: 25 July 2019 Accepted: 19 December 2019 Published online: 09 January 2020

References

1. Vigo D, Thornicroft G, Atun R. Estimating the true global burden of mental illness. Lancet Psychiatry. 2016;3:171-8.

2. Kawakami N, Takeshima T, Ono Y, Uda H, Hata Y, Nakane Y, Nakane H, Iwata N, Furukawa TA, Kikkawa T. Twelve-month prevalence, severity, and treatment of common mental disorders in communities in Japan: preliminary finding from the World Mental Health Japan Survey 2002-2003. Psychiatry Clin Neurosci. 2005;59:441-52.

3. Alexopoulos GS. Depression in the elderly. Lancet. 2005;365:1961-70.

4. Gottfried ED, Christopher SC. Mental disorders among criminal offenders: a review of the literature. J Correct Health Care. 2017:23:336-46.

5. Brhlikova P, Pollock AM, Manners R. Global burden of disease estimates of depression--how reliable is the epidemiological evidence? J R Soc Med. 2011;104:25-34

6. Lépine JP, Briley M. The increasing burden of depression. Neuropsychiatr Dis Treat. 2011;7:3-7.

7. Owen L, Corfe B. The role of diet and nutrition on mental health and wellbeing. Proc Nutr Soc. 2017:76:425-6.

8. Lang UE, Beglinger C, Schweinfurth N, Walter M, Borgwardt S. Nutritional aspects of depression. Cell Physiol Biochem. 2015;37:1029-43.

9. Molendijk M, Molero P, Ortuño Sánchez-Pedreño F, Van der Does W, Angel Martínez-González M. Diet quality and depression risk: a systematic review and dose-response meta-analysis of prospective studies. J Affect Disord. 2018:226:346-54

10. Rahe C, Unrath M, Berger K. Dietary patterns and the risk of depression in adults: a systematic review of observational studies. Eur J Nutr. 2014;53:997-1013.

11. Martínez-González MA, Sánchez-Villegas A. Food patterns and the prevention of depression. Proc Nutr Soc. 2016;75:139-46.

12. Lai JS, Hiles S, Bisquera A, Hure AJ, McEvoy M, Attia J. A systematic review and meta-analysis of dietary patterns and depression in communitydwelling adults. Am J Clin Nutr. 2014:99:181-97.

13. Schefft C, Kilarski LL, Bschor T, Köhler S. Efficacy of adding nutritional supplements in unipolar depression: a systematic review and meta-analysis. Eur Neuropsychopharmacol. 2017;27:1090-109. 
14. Goldberg DP, Gater R, Sartorius N, Ustun TB, Piccinelli M, Gureje O, Rutter C. The validity of two versions of the GHQ in the WHO study of mental illness in general health care. Psychol Med. 1997;27:191-7.

15. Hamajima N, J-MICC Study Group. The Japan Multi-Institutional Collaborative Cohort Study (J-MICC Study) to detect gene-environment interactions for cancer. Asian Pac J Cancer Prev. 2007:8:317-23.

16. Hattori $Y$, Naito M, Satoh M, Nakatochi M, Naito H, Kato M, Takagi S, Matsunaga T, Seiki T, Sasakabe T, et al. Metallothionein MT2A A-5G polymorphism as a risk factor for chronic kidney disease and diabetes: cross-sectional and cohort studies. Toxicol Sci. 2016;152:181-93.

17. Asai $Y$, Naito M, Suzuki M, Tomoda A, Kuwabara M, Fukada Y, Okamoto A, Oishi S, Ikeda K, Nakamura T, et al. Baseline data of Shizuoka area in the Japan Multi-Institutional Collaborative Cohort Study (J-MICC Study). Nagoya J Med Sci. 2009;71:137-44.

18. Doi Y, Minowa M. Factor structure of the 12-item general health questionnaire in the Japanese general adult population. Psychiatry Clin Neurosci. 2003;57:379-83.

19. Goldberg DP, Oldehinkel T, Ormel J. Why GHQ threshold varies from one place to another. Psychol Med. 1998;28:915-21.

20. Nanri H, Nishida Y, Nakamura K, Tanaka K, Naito M, Yin G, Hamajima N, Takashima N, Suzuki S, Nindita Y, et al. Associations between dietary patterns, ADR 32 GIn27Glu and ADRß3 Trp64Arg with regard to serum triglyceride levels: J-MICC study. Nutrients. 2016;8:545.

21. Imaeda N, Goto C, Tokudome Y, Hirose K, Tajima K, Tokudome S. Reproducibility of a short food frequency questionnaire for Japanese general population. J Epidemiol. 2007;17:100-7.

22. Tokudome Y, Goto C, Imaeda N, Hasegawa T, Kato R, Hirose K, Tajima K, Tokudome $S$. Relative validity of a short food frequency questionnaire for assessing nutrient intake versus three-day weighed diet records in middleaged Japanese. J Epidemiol. 2005;15:135-45

23. Tokudome S, Goto C, Imaeda N, Tokudome Y, Ikeda M, Maki S. Development of a data-based short food frequency questionnaire for assessing nutrient intake by middle-aged Japanese. Asian Pac J Cancer Prev. 2004;5:40-3.

24. Science and Technology Agency Japan. Standard Tables of Food Composition in Japan 5th revised edition. Tokyo: Printing Bureau, Ministry of Finance; 2000

25. Hara M, Higaki Y, Taguchi N, Shinchi K, Morita E, Naito M, Hamajima N, Takashima N, Suzuki S, Nakamura A, et al. Effect of the PPARG2 Pro12Ala polymorphism and clinical risk factors for diabetes mellitus on $\mathrm{HbA1C}$ in the Japanese general population. J Epidemiol. 2012;22:523-31.

26. Peduzzi P, Concato J, Kemper E, Holford TR, Feinstein AR. A simulation study of the number of events per variable in logistic regression analysis. J Clin Epidemiol. 1996;49:1373-9.

27. Shabbir F, Patel A, Mattison C, Bose S, Krishnamohan R, Sweeney E, Sandhu S, Nel W, Rais A, Sandhu R, et al. Effect of diet on serotonergic neurotransmission in depression. Neurochem Int. 2013;62:324-9.

28. Li B, LV J, Wang W, Zhang D. Dietary magnesium and calcium intake and risk of depression in the general population: a meta-analysis. Aust N Z J Psychiatry. 2017;51:219-29.

29. Knapp S, Mandell AJ, Bullard WP. Calcium activation of brain tryptophan hydroxylase. Life Sci. 1975;16:1583-93.

30. Tankeu AT, Ndip Agbor V, Noubiap JJ. Calcium supplementation and cardiovascular risk: a rising concern. J Clin Hypertens (Greenwich). 2017;19:640-6.

31. Reid IR, Birstow SM, Bolland MJ. Calcium and cardiovascular disease. Endocrinol Metab (Seoul). 2017;32:339-49.

32. Moore K, Hughes CF, Ward M, Hoey L, McNulty H. Diet, nutrition and the ageing brain: current evidence and new directions. Proc Nutr Soc. 2018:77: 152-63.

33. Herbison CE, Hickling S, Allen KL, O'Sullivan TA, Robinson M, Bremner AP, Huang RC, Beilin LJ, Mori TA, Oddy WH. Low intake of B-vitamins is associated with poor adolescent mental health and behaviour. Prev Med. 2012;55:634-8

34. Gautam M, Agrawal M, Sharma P, Gautam AS, Gautam S. Role of antioxidants in generalised anxiety disorder and depression. Indian J Psychiatry. 2012;54:244-7.

35. Deacon G, Kettle C, Hayes D, Dennis C, Tucci J. Omega 3 polyunsaturated fatty acids and the treatment of depression. Crit Rev Food Sci Nutr. 2017;57:212-23.

36. Grosso G, Galvano F, Marventano S, Malaguarnera M, Bucolo C, Drago F, Caraci F. Omega-3 fatty acids and depression: scientific evidence and biological mechanisms. Oxidative Med Cell Longev. 2014;2014:313570.
37. Meyer BJ. Are we consuming enough long chain omega-3 polyunsaturated fatty acids for optimal health? Prostaglandins Leukot Essent Fat Acids. 2011;85:275-80.

38. Grosso G, Micek A, Marventano S, Castellano S, Mistretta A, Pajak A, Galvano F. Dietary n-3 PUFA, fish consumption and depression: a systematic review and meta-analysis of observational studies. J Affect Disord. 2016;205:269-81.

39. National Health and Nutrition Examination Survey. Ministry of Health, Labor and Welfare 2017

40. Matsuoka YJ, Sawada N, Mimura M, Shikimoto R, Nozaki S, Hamazaki K, Uchitomi Y, Tsugane S. Dietary fish, n-3 polyunsaturated fatty acid consumption, and depression risk in Japan: a population-based prospective cohort study. Transl Psychiatry. 2017;7:e1242.

41. Sánchez-Villegas A, Verberne L, De Irala J, Ruíz-Canela M, Toledo E, SerraMajem L, Martínez-González MA. Dietary fat intake and the risk of depression: the SUN project. PLoS One. 2011;6:e16268.

42. Cui Y, Huang C, Momma H, Ren Z, Sugiyama S, Guan L, Niu K, Nagatomi R. Consumption of low-fat dairy, but not whole-fat dairy, is inversely associated with depressive symptoms in Japanese adults. Soc Psychiatry Psychiatr Epidemiol. 2017:52:847-53.

43. Perez-Cornago A, Sanchez-Villegas A, Bes-Rastrollo M, Gea A, Molero P, Lahortiga-Ramos F, Martínez-González MA. Intake of high-fat yogurt, but not of low-fat yogurt or prebiotics, is related to lower risk of depression in women of the SUN cohort study. J Nutr. 2016;146:1731-9.

44. Hori D, Tsujiguchi H, Kambayashi Y, Hamagishi T, Kitaoka M, Mitoma J, Asakura H, Suzuki F, Anyenda EO, Nguyen TT, et al. The associations between lifestyles and mental health using the general health questionnaire 12-items are different dependently on age and sex: a population-based cross-sectional study in Kanazawa, Japan. Environ Health Prev Med. 2016:21:410-21

45. López-León S, Janssens AC, González-Zuloeta Ladd AM, Del-Favero J, Claes SJ, Oostra BA, van Duijn CM. Meta-analyses of genetic studies on major depressive disorder. Mol Psychiatry. 2008;13:772-85.

46. Gorwood PH. Is anxiety hereditary? Encephale. 1998;24:252-5.

47. Head J, Stansfeld SA, Ebmeier KP, Geddes JR, Allan CL, Lewis G, Kivimäki M. Use of self-administered instruments to assess psychiatric disorders in older people: validity of the general health questionnaire, the Center for Epidemiologic Studies Depression Scale and the self-completion version of the revised clinical interview schedule. Psychol Med. 2013;43:2649-56.

\section{Publisher's Note}

Springer Nature remains neutral with regard to jurisdictional claims in published maps and institutional affiliations.

Ready to submit your research? Choose BMC and benefit from:

- fast, convenient online submission

- thorough peer review by experienced researchers in your field

- rapid publication on acceptance

- support for research data, including large and complex data types

- gold Open Access which fosters wider collaboration and increased citations

- maximum visibility for your research: over $100 \mathrm{M}$ website views per year

At $\mathrm{BMC}$, research is always in progress.

Learn more biomedcentral.com/submission 